\title{
The Influence of an International Festival on Visitors' Attitudes toward Diverse Cultures
}

\author{
Yao-Yi Fu \\ Indiana University, School of Health and Human Sciences, USA \\ yafu@iupui.edu \\ Suosheng Wang \\ Indiana University, School of Health and Human Sciences, USA \\ suwang@iupui.edu \\ Carina King \\ Indiana University, School of Health and Human Sciences, USA \\ carking@indiana.edu \\ Yung-Tsen Chu \\ Indiana University, School of Health and Human Sciences, USA \\ chuyung@umail.iu.edu
}

Interacting with people from other countries can enhance our knowledge of cultural diversity and provide an international perspective. There are many ways of enhancing cultural understanding, one of which is attending international festivals. While research on festivals is fast growing, visitors' attitudes toward diverse cultures is a relatively unexplored subject. This study used a visitor attitude scale to investigate visitors' behavioural, cognitive, and/or affective components of diversity attitudes. The research focused on measuring visitation frequency, stay-time at the event, similar event participation, cultural interest, and overseas travel experience contributing to any observed differences in visitors' attitudes. The visitors' intention to travel overseas after attending this festival was also investigated. A total of 195 visitors were surveyed on site at an international festival in a Midwestern city in the Us, with 176 providing usable data. The findings suggest that international festivals play an important role in improving visitors' awareness, appreciation, and acceptance of diverse cultures. Specifically, visitation frequency, the time spent at the event, and personal interest in cultures have significant influence on attitudes. These findings have implications for future researchers and event organisers.

Keywords: international festivals, ethnic groups, visitor attitude, diverse cultures https://doi.org/10.26493/2335-4194.11.127-141

\section{Introduction}

In this era of globalisation, there are more opportunities to meet many ethnic groups in our daily lives, whether in schools, in the workplace, in the private sector, or in government. Interacting with people from other countries can enhance our knowledge of cultural diversity and provide us with an international perspective (Allport, 1954). However, conflicts may happen due to the misunderstanding of cultural differences (Berry, 2005). Cross-cultural interaction and commu- 
nication can increase awareness of similarities and differences so that people can better appreciate and respect each other (Berry, 2005).

There are many ways of enhancing cultural understanding, including travelling overseas, visiting museums, attending cultural events, etc. Travel abroad may be the most direct way of interacting with different cultures; however, travel is not available for everyone. Fortunately, there are increasing numbers of multicultural activities in which people can participate.

For example, Indianapolis is the 12th largest city in the United States and has several cultural festivals throughout the year, including Brazil Carnival, Italian Street Festival, Indiana Latino Expo, Indiana Black Expo, Greek Fest, Irish Fest, German Fest, and others. Among those festivals, the oldest and largest ethnic celebration in central Indiana is the annual INDY International Festival.

The INDy International Festival has taken place since 1976. For the past few decades, the Nationalities Council of Indiana, a non-profit organisation composed of several ethnic groups has had a mission to promote cultural and ethnic activities, to increase communication, cultural exchange among people of all nationalities, races, and cultures, and to support the cultural and ethnic activities of their member groups and other organisations. The INDY International Festival is the signature event of the Nationalities Council of Indiana. It fully demonstrates the value of the $\mathrm{Na}$ tionalities Council of Indiana, displays Indiana's ethnic diversity, celebrates unique ethnic traditions, and encourages cultural exchange.

The INDY International Festival can be classified as a one-time, recurring event with a particular theme each year (e.g., the theme for 2017 was visual arts around the world) that people can participate in, learn from, and enjoy. Every year, the INDY International Festival includes a variety of events, such as a parade of nations, street painting, continuous ethnic music and dance by local and national performing groups, and Culture Booths where Indiana residents can learn and connect with other national heritages. At the same time, the festival provides authentic foods and handicrafts that Indiana residents can sample from around the world.
The INDY International Festival has been through many changes. It started as a street festival organised by the partnership of the International Center and $\mathrm{Na}$ tionalities Council of Indiana (hereafter NCI). Since most members of NCI are volunteers and only a few national groups are large enough to be self-supported, NCI had been working with a promotion company on the INDY International Festival. However, 2014 was the last year of their contract. It was a new beginning for NCI to run this event without the support of the promotion company in 2015.

The INDY International Festival is a four-day event on one weekend in November. Although it is an openfor-public event, it also sets aside specific times only for schools. Schools within a radius of 100 miles can apply for special school hours at the event. At least 200 schools have had field trips to the INDY International Festival. There were approximately 6,000 to 10,000 students and 10,000 adults, totalling 20,00025,000 visitors each year. $15-20 \%$ were repeat visitors, and $80 \%$ were first-time attendees.

\section{Purpose of the Study}

Very limited research has been conducted examining the visitors' attitudes toward diverse cultures in a festival setting. With the growing interest and enthusiasm for cultural festival events and the lack of information regarding visitors' attitudes and acceptance of cultural diversity, an in-depth analysis was thought to be necessary. Therefore, the purpose of the study was to examine the influence of the INDY International Festival on visitors' attitudes toward diverse cultures. Attempts were made to determine the extent to which visitors' visitation frequency, stay-time at the event, similar event participation, cultural interest, and overseas travel experience contributed to any observed differences, as would be indicated by the visitor attitude scale. Also, the visitors' intention to travel overseas after attending this festival was investigated. Specifically, the study sought to answer the following research questions:

1. Does attending the international festival in relation to visitation frequencies, visitors' personal interests, and past travelling experiences influence visitors' attitudes toward diverse cultures? 
2. Does attending the international festival motivate visitors to travel overseas? How well do the three measures of control (visitor attitude scale, visitation frequency, stay-time at the event) predict visitors' intention to travel abroad after attending this festival?

\section{Hypotheses}

The study was designed to test the following null hypotheses:

$\mathrm{H} 1$ There is no significant difference between firsttime and repeat visitors with their attitude (UDO) scores.

$\mathrm{H} 2$ There is no correlation between stay-time at the event and visitors' attitude (UDO) scores.

$\mathrm{H} 3$ There is no significant difference between visitors in relation to their past experiences in participating in international events and their attitude (UDO) scores.

$\mathrm{H} 4$ There is no correlation between visitors' cultural interests and their attitude (UDO) scores.

$\mathrm{H} 5$ There is no significant difference between visitors in relation to their overseas travel experiences and their attitude (UDO) scores.

$\mathrm{H} 6$ Visitors' intention to travel overseas after attending the festival are not affected by their attitude (UDO) scores, visitation frequency, and stay-time at the event.

\section{Literature Review}

This section provides a review of literature related to the construct of Universal Diverse Orientation (UDO) that was adopted by this research. Next, the MivilleGuzman Universality-Diversity Scale that was developed to measure UDO is discussed. Finally, this section presents a review of festival research.

\section{Universal Diverse Orientation and Miville-Guzman Universality-Diversity Scale}

As human beings, we are alike in many ways yet different from each other. Knowing the similarity and differences between us can make our interactions with each other more effective. This common understanding of each other would break down barriers between people from a variety of cultural backgrounds (Vontress, 1979).

Universal-Diversity Orientation (hereafter UDO) is a construct the was developed and defined by Miville et al. (1999) as 'an attitude toward all other persons that is inclusive yet differentiating in that similarities and differences are both recognised and accepted; the shared experience of being human results in a sense of connectedness with people and is associated with a plurality or diversity of interactions with others' (p. 292). Simply stated, UDO describes an attitude of awareness, acceptance, connectedness and appreciation of both similarities (i.e., commonality of being human) and differences (i.e., diverse cultural factors such as race, gender, religion, and age) among people (Fuertes, Miville, Mohr, Sedlacek, \& Gretchen, 2000). UDO reflects cognitive, behavioural, and affective components of social attitudes, which yielded three factors of U D O value: Diversity of Contact, seeking the opportunities to interact with diverse social groups; Relativistic Appreciation, revealing the recognition of similarities and differences between diverse populations; and Comfort with Others, expressing a sense of connection with members of diverse cultures.

Meanwhile, Miville et al. (1999) created the MivilleGuzman Universality-Diversity Scale (M-GUDS) to measure the level of UDO as well as those three individual components of UDO. The M-GUDS is a 45item questionnaire with items that are rated on a 6point continuum ( $1=$ strongly disagree, $6=$ strongly agree). The scale yields a total score as well as scores from three 15 -item subscales. Reliability (i.e., internal consistency and stability) and validity (i.e., construct) of the M-GUDS have been assessed and evaluated through much research. A higher score indicates a higher level of U Do.

In a series of studies (Miville et al., 1999), the MGUDS was proved to have high levels of reliability internally (all correlations were approximately 0.90 and subscales were intercorrelated above 0.75 ) and significantly correlated with a number of other scales. The M-GUDS was found to be significantly and positively correlated with the Contact, Pseudo-Independence and Autonomy subscales of the White Racial Identity 
Attitude Scale (WRIAS) and negatively correlated with the Disintegration and Reintegration of the WRIAS and the Dogmatism Scale and the Homophobia Scale as well. The Perspective Taking and Empathic Concern subscales of the Empathy Scale were found to be significantly and positively correlated with the MGUDS. Also, the M-GUDS were positively correlated with healthy narcissism as Healthy Grandiose Self and Healthy Idealised Parental Image subscales of the Inventory of Self Psychology as well as the attitudes toward feminism and androgyny. The results indicated that UDO, as measured by the M-GUDS, is consistent internally and over time, and is significantly related to social attitudes on racial identity, gender (feminism), sexual orientation (homophobia), and some aspects of personality functioning as healthy narcissism.

Fuertes et al. (2000) concluded that 'UDO is best conceptualized as a unidimensional construct with behavioral, cognitive and affective components, rather than a multidimensional construct with three distinct but interrelated domains' (p. 158). Later, a 15item M-GUDS, Short Form (M-GUDS-s) was developed (Fuertes et al., 2000). The Short Form is conceptually similar to the original M-GUDS. The scores on the Short Form were adequately reliable and valid, and that presents some advantages over the original scale. First, the M-GUDS-S is shorter and can be quickly administered. The positive correlation between long and short forms indicated that the short form measures UDO as significantly as the long form. Second, the factor structure and scale relationship was more clarified. Third, the M-GUDS-s allowed UDo analysis using subscale scores. The evidence suggested that subscale scores measured distinct aspects of UDo yet differently predicted diversity-related attitudes and behaviours.

Due to the development of the tourism industry and the increasing discussion on cultural interaction, the researcher hopes that Indiana residents can better understand and appreciate different cultures through participation in international festivals. Although MGUDS is mostly used in the field of psychology and counselling, it can be tested in event study to evaluate visitors' attitudes toward diverse cultures in festival settings. For the purpose of this study, the researcher adapted the 15-item Miville-Guzman UniversalityDiversity Scale, Short Form (Fuertes et al., 2000) and modified the items to adapt them more appropriately for this particular event. The three-factor diversity attitudes measure structure: (a) Diversity of Contact visitors' interest in participating in diverse cultural activities; (b) Relativistic Appreciation - the impact of diverse cultural activities on self-understanding and personal growth; (c) Comfort with Differences - visitors' degree of comfort with individuals from diverse cultures, to test their level of Universal-Diverse Orientation (UDO), which refers to visitors' attitudes in recognising and accepting differences and similarities in others was used.

Three items were developed for each subscale (nine items total). The reliabilities of the nine-item UDO measure, as well as the three subscales, were high. This study explored relationships between event visitation frequency, stay-time at the event, personal cultural interest, overseas travel experiences, travel intention, and UDO overall and by the three subscales separately. This will allow the research to determine whether the relationships found are due to behavioural, cognitive, and/or affective components of diversity attitudes.

\section{Festival Research}

The United States is a nation of immigrants which means people often come into contact with people of different races in daily life. Such interactions have both positive and negative impacts. Generally speaking, people living in metropolitan areas such as New York and Chicago may have high levels of diversity awareness and acceptance because of the cultural diversity of cities (Zukin, 1998). According to the contact theory developed by Allport (1954), under certain conditions, interpersonal contact is a way to reduce prejudice as well as increase understanding and appreciation between different groups.

People can enhance their cultural understanding in many different ways including travelling overseas, visiting museums, attending cultural events, etc. (Chang, 2006; Falk \& Foutz, 2007). In this research, 'international' and 'multicultural' are interchangeable terms. The definition of a multicultural festival can be varied, from different researchers' points of view. Based 
on a combination of Duffy (2005) and McClinchey's (2008) definitions, multicultural festivals are 'public, multicultural-themed celebrations at which multiethnic people - including both ethnic minorities and members of dominant population - have an extraordinary as well as mutually beneficial experience' (Lee, Arcodia, \& Lee, 2012, p. 95). Multicultural festivals create a themed environment for people to feel cultural authenticity, to engage with others, to learn new things, to observe the similarities and differences among ethnic groups in a leisurely way. A previous study has indicated several characteristics of multicultural festivals, including social interaction, cultural celebration, cultural identity and expression (Lee et al., 2012). Studies indicated that multicultural festivals provide a place for ethnic minority groups to recall their memories and experiences of where they are originally from, and to express and share their culture with the public through festival activities. Festivals not only foster cultural acceptance within the community but also generate interaction between minorities and the dominant population, which can reduce prejudice and conflicts in society as well as promote social harmony (Lee et al., 2012).

With the growth of event tourism as an academic field, research focusing on festivals has been increasing. People today demand higher event quality and content. Event organisers need to consider not only the cultural value of festivals but also visitors' needs. Visitors have personal motivations to visit festivals (Uysal, Gahan, \& Martin, 1993; Nicholson \& Pearce, 2001; Lee, Lee, \& Wicks, 2004; Li \& Petrick, 2006; Wamwara-Mbugua \& Cornwell, 2009; Lee, Arcodia, \& Lee, 2012; Kim, Savinovic, \& Brown, 2013). Many festival studies emphasised the importance of visitors' motivation. Visitors' motivation can vary from person to person, from event to event, and even from ethnicity to ethnicity. Many researchers have developed their own theoretical frameworks of motivation study and identified several motivations. Among festival studies, some common motivations can be identified, including family togetherness, socialisation, escape, novelty, uniqueness, excitement, entertainment, education, attraction, cultural exploration, curiosity, entertainment, and others (Uysal et al., 1993; Nichol- son \& Pearce, 2001; Lee, Lee, \& Wicks, 2004; Li \& Petrick, 2006; Wamwara-Mbugua \& Cornwell, 2009; Lee, Arcodia, \& Lee, 2012; Kim et al., 2013). Motives can be different for different types of events (Crompton \& McKay, 1997). For example, people attending food festivals are more likely to be motivated by novelty. Furthermore, everyone has their own perspective and expectation of the events that they are going to visit. Personal characteristics such as age, gender, income level, and education would cause motivational differences (Tkaczynski \& Toh, 2014; Wooten \& Norman, 2007). Women and people with higher educational background tend to be knowledge-seeking while visiting cultural festivals.

Multicultural festivals are different from other single-focus festivals such as the Greek festival or the Irish festival; visitors may have multiple motivations when visiting a multicultural festival. Among various motivations, cultural exploration was identified as the most important motivation for a multicultural festival (Chang, 2006; Lee et al., 2012). However, for those visitors whose culture is presented in a multicultural festival and those whose culture is not presented, their motivations are slightly different. Those whose cultures were not presented were more likely to seek connections of previous life experience, family or friends of a different cultural origin, and their personal interest in a multicultural festival. In contrast, those whose cultures were presented were more likely to celebrate their own cultural traditions (Huang \& Lee, 2015).

Because event organisers hope that festivals will not be a one-time event but a sustainable one, understanding visitors' motivations is necessary. To maintain a recurring festival, keeping those repeat visitors is the key. Repeat visitors not only spend more money in the festival, but also stay longer, are more likely to return, and possibly recommend the festivals to others (Shani, Rivera, \& Hara, 2009). As a result, understanding visitors' motivations is crucial for event organisers to build effective marketing strategies and meet the needs of festival visitors.

In addition to encouraging visitors to return, event organisers should consider the amount of time spent at the festival. One applicable study by Falk (1982) focused on the time spent at a museum as a measure 
of visitor behaviour. The research divided visitors into two categories: 'window shoppers' and 'serious shoppers.' The 'window shoppers' go to a museum to pass the time in a leisurely way. They try to see as many exhibitions as they can in the shortest amount of time. Therefore, good displays, clear access and space, and signage are important to them. In contrast, the 'serious shoppers' come with a purpose; they know what they want to see and they will spend time on a particular exhibition. Nevertheless, a 'window shopper' can turn into 'serious shopper.' If they discover something interesting, they will spend more time than they originally planned and may come back again. In conclusion, the time a visitor spends is an important factor that contributed to his/her behaviour (Falk, 1982). Therefore, it could be assumed that visitors' behaviour and even their attitudes can be changed after spending more time at the festival. Visitors may be attracted to the festival by different motivations, but the content that the festival provided can influence their behaviour.

Although many studies discuss the benefits that festivals bring to the community, research specifically on the values and benefits gained from festivals on the personal level remains limited. Visitor benefits in the festival context are defined as 'the ultimate value that people place on what they believe they have gained from observation or participation in activities provided by a festival' (Lee et al., 2012, p. 335). Having a comprehensive understanding of visitor benefits allows event organisers to evaluate the effectiveness of festivals. Such effectiveness could be an indicator of what the event offers, how the event programme and activities are executed, and what the event experience means to visitors. In terms of the benefits gained from attending festivals, a group of researchers using several benefit scales to test the outcome identified four key factors: social, cognitive, transformational, and affective benefits (Lee et al., 2012). The test results showed transformational benefit was the greatest benefit that visitors gained from attending a multicultural festival. In museum studies, 'transformational' was defined as discarding old ways of thinking, exploring new ideas and concepts (Soren, 2009), developing new attitudes, appreciation, and beliefs (Lord, 2007). There- fore, festivals have the potential to change visitors' attitudes and give them a positive perspective on different cultures.

The majority of the reviewed publications on festival study focus on marketers' perspectives. At the individual level, many of the resources emphasised visitor motivations, along with the festival visitors' satisfaction and behavioural intentions, but few studies have discussed the value and benefits gained from attending international festivals. Moreover, attitude and behavioural changes after the event have rarely been discussed.

In this study, the researcher intends to determine if the visitors' attitude toward diverse cultures would be influenced after attending the INDY International Festival. Due to a lack of relevant research, the researcher adopted the construct of Universal-Diversity Orientation from the psychological field and modified the items of M-GUDS-s to examine visitors' attitudes toward diverse culture.

\section{Methodology}

An on-site survey was conducted. The samples of the study were attendees of the 38th Annual INDY International Festival, which lasted four days. Participants were approached via convenience sampling on site at various times. Due to the objective of examining attitudes of visitors towards diverse culture in this study, the researcher tried to approach subjects from different races to survey. The researcher collected 195 surveys of which 176 had usable data.

The research instrument was designed to test the visitors' attitude toward diverse culture based on the construct of Universal-Diverse Orientation (UDO) and the development of the Miville-Guzman UniversalityDiversity Scale, Short Form (M-GUDS-s) by Miville et al. (1999). The questionnaire can be seen in Appendix $B$ and consisted of three parts: (a) 9-item questionnaire adapted from M-GUDS-S; (b) 11-item questionnaire of past experience at the event and other culture-related experience; and (c) 8-item questionnaire of included demographic variables.

There were several differences between the scale items in this research and original M-GUDS-S. The original 15-item M-GUDS-S can be seen in Table 1 . The 
Table 1 The Miville-Guzman Universality-Diversity Scale-Short Form

\begin{tabular}{ll}
\hline Aspect & Item \\
\hline Diversity of & 1. I would like to join an organization that emphasizes getting to know people from different countries. \\
Contact & $\begin{array}{l}\text { 2. I would like to go to dances that feature music from other countries. } \\
\text { 3. I often listen to the music of other cultures. } \\
\text { 4. I am interested in learning about the many cultures that have existed in this world. } \\
\text { 5. I attend events where I might get to know people from different racial backgrounds. }\end{array}$ \\
\hline Relativistic & 1. Persons with disabilities can teach me things I could not learn elsewhere. \\
Appreciation & 2. I can best understand someone after I get to know how he/she is both similar and different from me. \\
& $\begin{array}{l}\text { 3. Knowing how a person differs from me greatly enhances our friendship. } \\
\text { 4. In getting to know someone, I like knowing both how he/she differs from me and is similar to me. }\end{array}$ \\
& 5. Knowing about the different experiences of other people helps me understand my own problems better. \\
\hline Comfort With & $\begin{array}{l}\text { 1. Getting to know someone of another race is generally an uncomfortable experience for me. } \\
\text { Differences }\end{array}$ \\
& 2. I am only at ease with people of my own race. \\
3. It's really hard for me to feel close to a person form another race. \\
4. It is very important that a friend agrees with me on most issues. \\
5. I often feel irritated by persons of a different race.
\end{tabular}

Table 2 Modified M-GUDS-s Items

\begin{tabular}{ll}
\hline Aspect & Item \\
\hline Diversity of & $\begin{array}{l}\text { 1. Helps me know more people from different countries. } \\
\text { Contact }\end{array}$ \\
& $\begin{array}{l}\text { 2. Makes me more interested in trying different foods from other countries. } \\
\text { 3. Makes me more interested in learning about different cultures. }\end{array}$ \\
\hline Relativistic & 4. Teaches me more things that I could not learn elsewhere. \\
Appreciation & 5. Helps me best understand someone by knowing how he/she is similar to and different from me. \\
& 6. Increases my self-understanding by knowing other people's cultural background. \\
\hline Comfort with & 7. Makes me feel a sense of kinship with persons from different ethnic group. \\
Differences & $\begin{array}{l}\text { 8. Makes me become comfortable getting to know people from different countries. } \\
\text { 9. Makes me become more empathetic after knowing more people of different races. }\end{array}$ \\
\hline
\end{tabular}

scale in this research was modified from the original and reduced from fifteen to nine items because a few items from the original did not pertain to the population and geographical site of the study. For example, 'I would like to go to dances that feature music from other countries (Diversity of Contact),' 'Persons with disabilities can teach me things I could not learn elsewhere (Relativistic Appreciation), and 'It is very important that a friend agrees with me on most issues (Comfort with Differences)' do not fit quite right in this study; therefore, the researcher eliminated these few items from the original. It was the first time the M-GUDS-S was used in an event study. In order to suit the research objectives, the researcher rephrased the items and reduced the original M-GUDS-S from five to three items per aspect. Items are rated on a 6-point Likert type scale, ranging from 1 for 'strongly disagree' to 6 for 'strongly agree.' Higher scores on the M-G U DS$s$ reflect higher levels of UDO. In addition to being a reliable scale, the reliability of the M-GUDS-s has been tested and found to be o.90. Table 2 displayed the M-GUDS-S items as they pertain to three aspects of UDO.

The study analysed several factors influencing the UD O scores including visitation frequencies, length of stay during the visit, interests in culture, and past international travelling experience. In order to obtain the demographic data of festival visitors, the following 
Table 3 Respondent Profile

\begin{tabular}{|c|c|c|c|}
\hline Variable & Group & $N$ & $\%$ \\
\hline \multirow[t]{3}{*}{ Gender } & Male & 82 & 47.1 \\
\hline & Female & 92 & 52.9 \\
\hline & Total & 174 & 100 \\
\hline \multirow[t]{6}{*}{ Age } & $18-28$ & 47 & 27.6 \\
\hline & $29-38$ & 49 & 28.8 \\
\hline & $39-48$ & 34 & 20.0 \\
\hline & $49-58$ & 21 & 12.4 \\
\hline & $59+$ & 19 & 11.2 \\
\hline & Total & 170 & 100 \\
\hline \multirow[t]{5}{*}{ Marital Status } & Single & 77 & 44.8 \\
\hline & Married & 80 & 46.5 \\
\hline & Divorced/Partnered & 12 & 7.0 \\
\hline & Widowed & 3 & 1.7 \\
\hline & Total & 172 & 100 \\
\hline \multirow[t]{4}{*}{ Education } & High School & 19 & 11.2 \\
\hline & College & 95 & $55 \cdot 9$ \\
\hline & Post-Graduate & 56 & 32.9 \\
\hline & Total & 170 & 100 \\
\hline \multirow[t]{6}{*}{ Race } & Caucasian & 113 & $65 \cdot 3$ \\
\hline & African American & 11 & 6.4 \\
\hline & Hispanic & 7 & 4.0 \\
\hline & Asian/Pacific Islander & 30 & $17 \cdot 3$ \\
\hline & Others & 12 & 6.9 \\
\hline & Total & 173 & 100 \\
\hline
\end{tabular}

Continued in the next column

questions were asked: (1) gender; (2) age; (3) marital status; (4) race; (5) education; (6) annual household income before taxes; (7) employment status; (8) residence zip code.

\section{Results}

Descriptive Profile of the Respondents

Overview of item frequencies and descriptive statistics permitted assurance of accuracy across all questionnaire items. Upon further review, input errors were identified and corrected. In total, 195 questionnaires were collected from visitors to the INDY International Festival, with 176 (90\%) questionnaires usable. The de-
Table 3 Continued

\begin{tabular}{llrr}
\hline Variable & Group & $N$ & $\%$ \\
\hline Annual Household & Less than $\$ 25,000$ & 31 & 19.5 \\
Income & $\$ 25,001-\$ 50,000$ & 50 & 31.4 \\
& $\$ 50,001-\$ 100,000$ & 53 & 33.3 \\
& $\$ 100,000+$ & 25 & 15.7 \\
& Total & 159 & 100 \\
\hline Employment Status & Employed & 132 & 77.2 \\
& Unemployed & 12 & 7.0 \\
& Retired & 13 & 7.6 \\
& Others & 14 & 8.2 \\
& Total & 171 & 100 \\
\hline
\end{tabular}

Table 4 Correlations among Modified M-GuDs-s Full Scale and Subscales

Scale/subscale

(1)

(2)

(3)

(4)

\begin{tabular}{lllll}
\hline (1) Diversity of Contact & \multicolumn{1}{l}{$l$} & & \\
(2) Relativistic Apprec. & $0.578^{* *}$ & - & & \\
(3) Comfort With Diff. & $0.685^{* *} 0.696^{* *}$ & - & \\
(4) UDo Full Scale & $0.839^{* *} 0.874^{* *} 0.915^{* *}$ & - \\
\hline
\end{tabular}

mographic characteristics of the participants are presented in Table 3. This table demonstrated that the gender distribution of festival visitors was quite even, with 82 male (47.1\%) and 92 female (52.9\%). The age groups that recorded the highest attendance at the festival were the 18 -to- 28 age group (27.6\%) and the 29 to-38 age group (28.8\%). Marital status single (44.8\%) and married (46.5\%) were quite even. For the education level of respondents, over half of the respondents (55.9\%) had a college education, and $56(32.9 \%)$ were post-graduate. In terms of race, the majority of respondents were Caucasian (65.3\%), with 17.3\% Asians and Pacific Islanders. The annual household income of respondents was between the range of $\$ 25,001$ to $\$ 50,000(31.4 \%)$ and \$50,001 to \$100,000 (33.3\%). Most of the respondents were employed $(77.2 \%)$.

\section{The Visitor Attitude Scale}

The Visitor Attitude Scale in this research was adopted from the original 15-item M-GUDS-s by Miville et al. 
Table 5 Means and Standard Deviations of the Items

\begin{tabular}{|c|c|c|}
\hline Items & Mean & SD \\
\hline Makes me more interested in trying different foods from other countries (DC) & $5 \cdot 39$ & 0.771 \\
\hline Makes me more interested in learning about different cultures (DC) & 5.37 & 0.767 \\
\hline Helps me know more people from different countries (DC) & 5.11 & 0.810 \\
\hline Makes me feel a sense of kinship with persons from different ethnic group (CD) & 5.09 & 0.861 \\
\hline Makes me become more empathetic after knowing more people of different races (CD) & 5.03 & 0.935 \\
\hline Helps me best understand someone by knowing how he/she is similar to and different from me (RA) & 5.03 & 0.845 \\
\hline Makes me become comfortable getting to know people from different countries (CD) & 4.99 & 0.956 \\
\hline Increases my self-understanding by knowing other people's cultural background (RA) & 4.96 & 0.858 \\
\hline Teaches me more things that I could not learn elsewhere (RA) & 4.90 & 0.895 \\
\hline
\end{tabular}

Notes DC - Diversity of Contact, CD - Comfort with Differences, R A - Relativistic Appreciation. $N=176$.

Table 6 Results of $t$-Tests and Descriptive Statistics of Full Scores and Subscale Scores by Visitation Frequency

\begin{tabular}{|c|c|c|c|c|c|c|c|c|c|}
\hline \multirow[t]{2}{*}{ Outcome } & \multicolumn{3}{|c|}{ First-time visitors } & \multicolumn{3}{|c|}{ Repeat visitors } & \multirow[t]{2}{*}{ Sig. } & \multirow[t]{2}{*}{$t$} & \multirow[t]{2}{*}{$\mathrm{DF}$} \\
\hline & Mean & SD & $n$ & Mean & SD & $n$ & & & \\
\hline Diversity of Contact & 5.18 & 0.61 & 91 & 5.40 & 0.61 & 85 & $0.018^{\star}$ & -2.391 & 174 \\
\hline Relativistic Appreciation & 4.80 & 0.81 & 91 & 5.14 & 0.65 & 85 & $0.003^{* *}$ & -3.044 & 174 \\
\hline Comfort with Difference & 4.90 & 0.87 & 91 & 5.18 & 0.69 & 85 & $0.018^{\star}$ & -2.380 & 174 \\
\hline Universal-Diverse Orientation & 4.96 & 0.67 & 91 & 5.24 & 0.56 & 85 & $0.003^{* *}$ & -2.988 & 174 \\
\hline
\end{tabular}

Notes ${ }^{\star} p<0.05,{ }^{* *} p<0.01$ (two-tailed).

(2000) and reduced from five to three items per subscale. The reliability of all items as well as three subscales was tested using Cronbach's alpha. Cronbach's alpha for the 9-item UDO measure was 0.90, whereas coefficient alphas for the subscales were $0.70,0.84$, and 0.84 , for diversity of contact, relativistic appreciation, and comfort with difference, respectively. Subscales were found to be significantly inter-correlated with each other as well as with the full scale (Table 4).

Table 5 provided the mean scores of the M-GUDS-S items in descending order. The M-GUDS-S were measured on a 6-point Likert type scale with 1 synonymous with 'strongly disagree,' 2 synonymous with 'disagree,' 3 synonymous with 'disagree a little bit', 4 synonymous with 'agree a little bit', 5 synonymous with 'agree,' and 6 synonymous with 'strongly agree.'

The mean scores of items were between 4.9 to 5.39. The average score of all items was 5.1. The two items with the highest means measuring visitor attitudes were 'Item 2: Makes me more interested in trying different foods from other countries' $(M=5.39)$ and 'Item 3: makes me more interested in learning about different cultures' $(M=5.37)$, which were both located in the subscale of diversity of contact. In contrast, the two items with the lowest mean were 'Item 4: teaches me more things that I could not learn elsewhere' (4.90) and 'Item 6: increases my self-understanding by knowing other people's cultural background' (4.96), both located in the subscale of relativistic appreciation. The average scores of three subscales were 5.29 (Diversity of Contact), 4.96 (Relativistic Appreciation), and 5.03 (Comfort with Difference).

\section{Testing of Hypothesis 1}

From the usable data $(N=176)$, 91 respondents were first-time visitors (51.7\%) with 85 repeat visitors (48.3\%). An independent-samples $t$-test was conducted to examine whether there was a significant difference be- 
Table 7 Correlations among Modified M-GUDS-S Full Scores and Subscale Scores with Visitation Frequency

\begin{tabular}{|c|c|c|c|}
\hline Item & Visitation Frequency & Item & Stay-Time \\
\hline Visitation Frequency & - & Stay-time & - \\
\hline Diversity of Contact & $0.155^{\star}$ & Diversity of Contact & $0.176^{*}$ \\
\hline Relativistic Appreciation & $0.228^{* *}$ & Relativistic Appreciation & $0.218^{* *}$ \\
\hline Comfort with Difference & $0.163^{*}$ & Comfort with Difference & $0.195^{*}$ \\
\hline Universal-diverse Orientation & $0.209^{* *}$ & Universal-diverse Orientation & $0.224^{* *}$ \\
\hline
\end{tabular}

Table 8 Correlations among Modified M-GUDS-S Full Scores and Subscale Scores with Stay-Time

Table 9 Results of $t$-Tests and Descriptive Statistics of Full Scores and Subscale Scores by International Event Experience

\begin{tabular}{|c|c|c|c|c|c|c|c|c|c|}
\hline \multirow[t]{2}{*}{ Outcome } & \multicolumn{3}{|c|}{ (1) } & \multicolumn{3}{|c|}{ (2) } & \multirow[t]{2}{*}{ Sig. } & \multirow[t]{2}{*}{$t$} & \multirow[t]{2}{*}{$\mathrm{DF}$} \\
\hline & Mean & SD & $n$ & Mean & SD & $n$ & & & \\
\hline Diversity of Contact & 5.11 & 0.71 & 66 & 5.40 & 0.52 & 97 & $0.004^{* *}$ & -2.905 & 112 \\
\hline Relativistic Appreciation & 4.80 & 0.78 & 66 & 5.03 & 0.73 & 97 & 0.055 & -1.936 & 161 \\
\hline Comfort with Difference & 4.88 & 0.87 & 66 & 5.15 & 0.72 & 97 & $0.028^{\star}$ & -2.212 & 161 \\
\hline Universal-Diverse Orientation & 4.93 & 0.69 & 66 & 5.20 & 0.57 & 97 & $0.008^{\star *}$ & -2.696 & 161 \\
\hline
\end{tabular}

Notes (1) Didn't attend any international event. (2) Attended at least one international event in the last three years. ${ }^{\star} p<$ $0.05,{ }^{* *} p<0.01$ (two-tailed).

tween first-time and repeat visitors in relation to their overall UDo scores and each subscale. Table 6 revealed a significant difference in average UDO scores between first-time visitors $(\mathrm{M}=4.96, \mathrm{SD}=0.67)$ and repeat visitors $(\mathrm{M}=5.24, \mathrm{SD}=0.56 ; t(174)=-2.988, p$ $=0.003$, two-tailed). The magnitude of the differences in the means (mean difference $=-0.28,95 \% \mathrm{CI}:-0.47$ to -0.10$)$ was small $\left(\right.$ eta $\left.^{2}=0.049\right)$. There were also significant differences in the three subscales: Diversity of Contact $(p=0.018)$, Relativistic Appreciation $(p=$ o.003), and Comfort with Difference $(p=0.018)$.

In addition, the relationship between the numerical data of visitation frequencies and UDO scores were conducted by Pearson correlation analyses. A modest, positive correlation was found between visitation frequency and UDO scores $(r=0.21, p=0.008)$. Moreover, visitation frequencies were positively correlated with each subscale: Diversity of Contact $(r=0.16, p=$ o.049), Relativistic Appreciation $(r=0.23, p=0.003)$, and Comfort with Difference $(r=0.16, p=0.037)$ (Table 7).
Table 10 Correlations among Modified M-GUDS-S Full Score and Subscale Scores with Cultural Interest

\begin{tabular}{lr}
\hline Item & Cultural Interest \\
\hline Cultural Interest & - \\
DOC & $0.547^{* *}$ \\
RA & $0.380^{* *}$ \\
CWD & $0.437^{* *}$ \\
UDO & $0.510^{* *}$ \\
\hline
\end{tabular}

Notes ${ }^{*} p<0.05,{ }^{* *} p<0.01$ (two-tailed).

\section{Testing of Hypothesis 2}

The relationship between visitors' UDO scores and their stay-time at the event was investigated using the Pearson product-moment correlation coefficient. There was a positive significant correlation between the two variables, $r=0.22, n=172, p=0.003$, with high levels of UDo scores associated with long staytime at the event (Table 8).

Moreover, stay-time was also positively correlated 
Table 11 Results of $t$-Tests and Descriptive Statistics of Full Scores and Subscale Scores by Oversea Travel Experience

\begin{tabular}{|c|c|c|c|c|c|c|c|c|c|}
\hline \multirow[t]{2}{*}{ Outcome } & \multicolumn{3}{|c|}{ Have traveled overseas } & \multicolumn{3}{|c|}{ Never traveled overseas } & \multirow[t]{2}{*}{ Sig. } & \multirow[t]{2}{*}{$t$} & \multirow[t]{2}{*}{ DF } \\
\hline & Mean & SD & $n$ & Mean & SD & $n$ & & & \\
\hline Diversity of Contact & $5 \cdot 30$ & 0.62 & 140 & 5.26 & 0.64 & 36 & 0.742 & 0.330 & 174 \\
\hline Relativistic Appreciation & 4.96 & 0.76 & 140 & 4.97 & 0.73 & 36 & 0.929 & -0.090 & 174 \\
\hline Comfort with Difference & 5.01 & 0.81 & 140 & 5.12 & 0.75 & 36 & 0.469 & -0.726 & 174 \\
\hline Universal-Diverse Orientation & 5.09 & 0.64 & 140 & 5.12 & 0.61 & 36 & 0.817 & -0.231 & 174 \\
\hline
\end{tabular}

Notes ${ }^{*} p<0.05,{ }^{* *} p<0.01$ (two-tailed).

with each subscale: Diversity of Contact $(r=0.18, p=$ $0.021)$, Relativistic Appreciation $(r=0.22, p=0.004)$, and Comfort with Difference $(r=0.20, p=0.01)$.

\section{Testing of Hypothesis 3}

An independent samples $t$-test was conducted to examine whether there was a significant difference between respondents who did not attend any international events (group $1, N=66,40 \%$ ) and those who had attended at least one international event in the previous three years (group 2, $N=97,60 \%$ ). There was a significant difference in UDO scores for group $1(\mathrm{M}=$ $4.93, \mathrm{SD}=0.69)$ and group $2(\mathrm{M}=5.20, \mathrm{SD}=0.57 ; t$ $(161)=-2.696, p=0.008$, two-tailed). The magnitude of the differences in the means (mean difference $=-$ $0.27,95 \%$ CI: -0.46 to -0.07$)$ was small $\left(e t a^{2}=0.043\right)$.

There were also significant differences in two subscales: Diversity of Contact $(p=0.004)$ and Comfort with Difference $(p=0.028)$, excluding Relativistic Appreciation $(p=0.055)$ (Table 9$)$.

\section{Testing of Hypothesis 4}

The relationship between visitors' UDO scores and their cultural interest was investigated using the Pearson product-moment correlation coefficient. There was a strong, positive correlation between the two variables, $r=0.51, n=176, p<0.001$, with high levels of cultural interest associated with high levels of UDO scores.

Also, the Pearson correlation coefficient is positive on each subscale: Diversity of Contact $(r=0.55, p<$ o.001), Relativistic Appreciation $(r=0.38, p<0.001)$, and Comfort with Difference $(r=0.44, p<0.001)$ respectively (Table 10).

\section{Testing of Hypothesis 5}

An independent samples $t$-test was conducted to examine whether there was a significant difference between respondents who had travelled overseas (Group $1, N=140,80 \%)$ and those who had never travelled overseas (Group 2, $N=36,20 \%$ ). There was no significant difference in UDO scores for group $1(\mathrm{M}=5.09$, $\mathrm{SD}=0.64)$ and group $2(\mathrm{M}=5.12, \mathrm{SD}=0.61 ; t(174)$ $=-0.231, p=0.817$, two-tailed). There were also no significant differences in the three subscales: Diversity of Contact $(p=0.742)$, Relativistic Appreciation ( $p=$ o.929), and Comfort with Difference $(p=0.469)$ (Table 11).

\section{Testing of Hypothesis 6}

A multiple linear regression was calculated to predict visitors' intention to travel overseas after attending this festival based upon their average UDO scores, visitation frequency, and stay-time at the event. In conducting the regression analysis, the variable of 'Overseas travel intention' served as the dependent variable, while three factors (UDO scores, visitation frequency and stay-time at the event) were used as the independent variables.

Preliminary analyses were performed to ensure there was no violation of the assumption of normality, linearity and multicollinearity. As illustrated in Table 12 , a significant regression equation was found $(F=$ $18.74, p<0.0001$ ), with an $R^{2}$ of 0.252 , which means that $25.2 \%$ of the total variance in the dependent variable can be explained by the variables in the model. The degree of variable collinearity is considered acceptable with the variance inflation (VIF) less than 10. Visitors' intention to travel is equal to $0.889+0.709$ 
Table 12 Overseas Travel Intention after Attending the Festival

\begin{tabular}{lrrrrr}
\hline Model & $(1)$ & $(2)$ & $(3)$ & $(4)$ & $(5)$ \\
\hline Regression & 30.946 & 3 & 10.315 & 18.740 & 0.000 \\
Residual & 85.318 & 155 & 0.550 & & \\
Total & 116.264 & 158 & & & \\
\hline
\end{tabular}

Notes Column headings are as follows: (1) sum of squares, (2) degrees of freedom, (3) mean square, (4) F, (5) significance. $R=0.516, R^{2}=0.266$, adjusted $R^{2}=0.252$

Table 13 Variables in the Equation

\begin{tabular}{lrrrr}
\hline Variable & $B$ & Beta & $t$ & Sig. \\
\hline Constant & 0.899 & & 1.867 & 0.064 \\
UDO & 0.709 & 0.530 & 7.421 & 0.000 \\
Stay-time & -0.066 & -0.162 & -2.216 & 0.028 \\
VF & -0.005 & -0.022 & -0.305 & 0.761 \\
\hline
\end{tabular}

Notes Dependent variable: Overseas travel intention after attending the festival.

(UDO) - 0.005 (visitation frequency) - 0.066 (staytime at the event) (Table 13).

\section{Discussions}

Using a quantitative approach, this paper explored the INDY International Festival visitors' attitudes toward diverse cultures and compared the differences between groups in relation to their visitation frequencies to this particular festival, past experiences in participating in international events, and overseas travel experiences. In addition, the relationship between stay-time at the event, personal, cultural interest and attitude scores were tested. Moreover, overseas travel intentions after attending this event were analysed.

Demographic data revealed several items worthy of note. The previous cultural event study concluded that gender, age, education, and income are some of the personal characteristics that influence motivations to attend multicultural festivals (Tkaczynski \& Toh, 2014). In this research, respondents were near equally distributed across each gender, with 82 male (47.1\%) and 92 female (52.9\%). Although the proportion of gender difference is not large here, it is obvious that females are more likely to be drawn into cultural events. Over half of the respondents were between the ages of 18 to 30 (56.4\%); 151 respondents $(88.8 \%)$ indicated that they had either some college education or a post-graduate degree. These two demographic factors indicated that the majority of visitors were highly educated young adults. It indicated that cultural events are more attractive to visitors who have high educational backgrounds. The findings showed the annual household income of respondents were between the range of $\$ 25,001$ to $\$ 50,000(31.4 \%)$ and $\$ 50,001$ to $\$ 100,000$ (33.3\%). Although it was concluded in other research that income was an indicator influencing visitors' decision to attend cultural events (Tkaczynski \& Toh, 2014), it is uncertain whether those with high or low income would participate in cultural events more often. More research needs to be done in order to find the rationale for this argument. Based on the record of the United States Census Bureau (2014), more than $80 \%$ of Indiana residents were White, and only 2.1\% were Asians/Pacific Islanders. The result of this research included 65.3\% Caucasian respondents and $17.3 \%$ Asians and Pacific Islanders respondents. The reason that the high percentage of Asians/Pacific Islanders attended this festival may be caused by their cultures' representation at the festival. Those whose cultures have presented would feel connections and have a sense of cultural self-esteem (Huang \& Lee, 2015).

The scale that tested visitors' attitudes in this study was adapted from M-GUDS, Short Form (Fuertes et al., 2000). The present findings suggested the scale has good reliability and validity and can be used successfully to measure visitors' attitudes toward diverse cultures in the festival setting. The average score of all respondents was 5.1 on the 6-point Likert type scale. Visitors as a whole had high attitude scores. The average score of three subscales were 5.29 (Diversity of Contact), 4.96 (Relativistic Appreciation), and 5.03 (Comfort with Difference) respectively. The mean scores of each item were between 4.9 to 5.39. The item with the highest score was 'Makes me more interested in trying different foods from other countries (Diversity of Contact)' (5.39).

In contrast, the item with the lowest score was 'Teaches me more things that I could not learn else- 
where (Relativistic Appreciation)' (4.90). Respondents' attitude scores on the subscale of Diversity of Contact were comparatively higher than the other two subscales. It revealed that this festival successfully created a comfortable interaction environment for visitors to learn and to try new things from different cultures. However, the scores on the subscale of Relativistic Appreciation were lower; this does not mean that the festival is not helpful in this aspect of attitudes. The results may be affected by how the researcher stated the questions and respondents' understanding of it.

In order to answer the research questions, six hypotheses were analysed. Differences were found between first-time visitors (51.7\%) and repeat visitors (48.3\%). Repeat visitors have higher attitude scores ( $M$ $=5.24)$ than first visitors $(\mathrm{M}=4.96)$ as well as on each subscale. In addition, stay-time at the event was positive and significantly correlated to visitors' attitude scores $(r=0.22, p=0.003)$. It is said that the more time spent at the festival and the more often visitors come, the better the understanding of cultural differences (Falk, 1982). With a longer period of exploration and involvement in the festival, visitors developed more in-depth understanding and appreciation for different cultures.

According to several motivation studies, cultural exploration was identified as the most important motivation to attend multicultural festivals (Crompton \& McKay, 1997; Chang, 2006; Lee et al., 2012). The findings of this study showed that visitors' cultural interest in visiting ethnic festivals and museums was positive and significantly correlated to visitors' attitude scores $(r=0.51, p<0.001)$. Differences were also found between those who had participated in international events in the previous three years than those who had not. Those who have participated in international events in the previous three years have higher attitude scores $(M=5.20)$ than those who had not participated in any international events $(M=4.93)$. It indicated that people who have interest in cultures would pay more attention to cultural events and their attitudes toward diversity are likely more positive than those who do not have an interest in cultures. Significant results were also seen on two subscales: Diversity of Contact and Comfort with Difference, ex- cluding the subscale of Relativistic Appreciation. The reason that Relativistic Appreciation is not significant for this particular group may be because those who have interest in cultures already have basic understanding of diverse cultures from their past experiences. They do not necessarily expect this particular festival to teach them something they cannot learn elsewhere. Compared with their past experiences, this festival was not beneficial on the aspect of Relativistic Appreciation.

In this study, visitors were asked about their overseas travel experience and were divided into two groups: one who had overseas travel experience and the other who had not travelled overseas. It was assumed that positive attitudes toward diverse cultures would be stronger after attending this festival in those with overseas travel experience than those who do not have the experience. However, there was no significant difference in UDO scores between those who have overseas travel experience $(M=5.09)$ and those who have not $(M=5.12)$. One possible reason for there being no statistical significance may lie in the small size of the never-been-overseas group. In the present study, only 36 participants $(20 \%)$ had never travelled overseas. Moreover, another possible reason may be that this festival does not give them much more to see than their experience in other countries. Therefore, it is unable to find a definitive answer from this study. Finally, this study analysed if attending this festival could increase visitors' overseas travel intention. A significant regression was found $(F=18.74, p<0.0001)$, with an $R^{2}$ of 0.252 . Visitors' intention to travel is equal to 0.889 +0.709 (UDO) - 0.005 (visitation frequency) - 0.066 (stay-time at the event). However, $25.2 \%$ of the total variance is not strong. There may be some related variables that were not included in the study.

\section{Conclusions}

This study aimed to determine if attending international festivals can improve visitors' attitudes toward diverse cultures. Several practical implications of the study could be useful to event organisers and even other multicultural organisations or communities hosting multicultural festivals. The findings of the study reflect that Indiana residents who attended 
this international festival have high attitude scores. Those who have high educational background may have encountered people from different ethnic groups in school or in the workplace. Their educational path gives them more opportunities to interact with different cultures, and it makes them have a different perspective on cultural diversity.

Moreover, for those who have an interest in cultural events and museums, their motivation in attending the festival was more purposeful. They only seek specific exhibits that interest them. If the festival can meet their needs, they will stay longer and perhaps visit again. International festivals play an important role in cultivating visitors' awareness, acceptance, and appreciative attitudes toward diverse cultures; understanding the levels of attitudes reveals the importance that international events can have and suggests how better to organise festivals for various groups of visitors.

This research has produced some significant findings. However, it is not without its limitations. The INDY International Festival is positioning itself to be the largest ethnic celebration in Indiana. While they are eager to promote cultural diversity in the city, it is difficult to evaluate if the festival is delivering their message to the visitors. Therefore, this study provides useful information on the visitors' profile. With the visitors' profile information, it would be easier to find target groups and consider ways to keep the groups the festival already have and attract different types of groups at the same time. Furthermore, without knowing visitor' attitudes toward diverse cultures before attending the festival, it is difficult to know if visitors' attitudes have changed because of the festival. In order to have an anticipated outcome, this study should be replicated each year at the festival.

\section{Recommendations}

Since it was a preliminary test on attitudes in the festival setting, further research is needed to explore the nuances of this study. The study could be replicated with a different group of visitors who go to the same event to determine if the results are similar. Since the INDY International Festival, where this study was conducted, is an annual local event in Indianapolis, a replication of the current study that compares vari- ous groups of visitors for each year would be powerful. A focus could be on exploring issues of age differences, racial differences, educational differences, etc. Additionally, comparing the results of the attitudes with other cultural events assessments would be useful. Other cultural events have equal contribution to promoting diversity. However, too many similar activities and events may dilute the crowd. If public sectors can integrate resources of local communities and organisations to utilise and share resources effectively, the contribution of cultural events would be more notable.

A central focus of this research addresses the missions of many multicultural events: to display cultural and ethnic diversity, increase communication, and encourage cultural exchange. As is evident in this research, a well-designed international festival could be an effective instrument. In an era of globalisation, multicultural events must make a significant impact for the society. Event organisers must find ways to develop educational, interactive, and amusing activities and programmes for local communities to embrace similarities and differences in our society.

The study has made two contributions. Theoretically, this study put forth measurement strategies that are more reflective as to what visitor's attitudes toward diverse cultures are when visiting multicultural festivals. Practically, the findings of this study will benefit central Indiana and other communities considering that international or so-called multicultural festivals play an important role in the tourism industry today. Festivals not only benefit the community economically but also psychologically. The greater demand for well-organised multicultural festivals justifies the need for more effective, accurate, quantifiable data. Thus, event organisers that consult the data derived from the results of this study will be able to organise events more efficiently and effectively.

\section{References}

Allport, G. W. (1954). The nature of prejudice. New York, NY: Addison.

Berry, J. W. (2005). Acculturation: Living successfully in two cultures. International Journal of Intercultural Relations 29(6), 697-712. 
Chang, J. (2006). Segmenting tourists to aboriginal cultural festivals: An example in the Rukai tribal area, Taiwan. Tourism Management, 27(6), 1224-1234.

Crompton, J. L., \& McKay, S. L. (1997). Motives of visitors attending festival events. Annals of Tourism Research, 24(2), 425-439.

Duffy, M. (2005). Performing identity within a multicultural framework. Social \& Cultural Geography, 6(5), 677-692.

Falk, J. H. (1982). The use of time as a measure of visitor behavior and exhibit effectiveness. Roundtable Reports, $7(4), 10-13$.

Falk, J. H., \& Foutz, S. (2007). In principle, in practice: $M u$ seums as learning institutions. Plymouth, England: Rowman Altamira.

Fuertes, J. N., Miville, M. L., Mohr, J. J., Sedlacek, W. E., \& Gretchen, D. (2000). Factor structure and short form of the Miville-Guzman Universality-Diversity Scale. Measurement and Evaluation in Counseling and Development, 33(3), 157-169.

Huang, S., \& Lee, I. S. (2015). Motivations for attending a multicultural festival: Visitor ethnicity matters. Anatolia, 26(1), 92-95.

Kim, S., Savinovic, A., \& Brown, S. (2013). Visitors' motivations in attending an ethnic minority cultural festival: A case study of the Fešta Croatian Food and Wine Festival, South Australia. Event Management, 17(4), 349-359.

Lee, I. S., Arcodia, C., \& Lee, T. J. (2012). Key characteristics of multicultural festivals: A critical review of the literature. Event Management, 16(1), 93-101.

Lee, C. K., Lee, Y. K., \& Wicks, B. E. (2004). Segmentation of festival motivation by nationality and satisfaction. Tourism management, 25(1), 61-70.

Li, X., \& Petrick, J. F. (2006). A review of festival and event motivation studies. Event Management, 9(4), 239-245.

Lord, B. (Ed.). (2007). The manual of museum learning. Plymouth, England: Rowman Altamira.

McClinchey, K. A. (2008). Urban ethnic festivals, neighborhoods, and the multiple realities of marketing place. Journal of Travel \& Tourism Marketing, 25(3-4), 251-264.
Miville, M. L., Gelso, C. J., Pannu, R., Liu, W., Touradji, P., Holloway, P., \& Fuertes, J. (1999). Appreciating similarities and valuing differences: The Miville-Guzman Universality-Diversity Scale. Journal of Counseling Psychology, 46(3), 291.

Nicholson, R. E., \& Pearce, D. G. (2001). Why do people attend events: A comparative analysis of visitor motivations at four South Island events. Journal of Travel Research, 39(4), 449-460.

Shani, A., Rivera, M. A., \& Hara, T. (2009). Assessing the viability of repeat visitors to cultural events: Evidence from the Zora! Festival. Journal of Convention \& Event Tourism, 10(2), 89-104.

Soren, B. J. (2009). Museum experiences that change visitors. Museum Management and Curatorship, 24(3), 233-251.

Tkaczynski, A., \& Toh, Z. H. (2014). Segmentation of visitors attending a multicultural festival: An Australian scoping study. Scandinavian Journal of Hospitality and Tourism, 14(3), 296-314.

Uysal, M., Gahan, L., \& Martin, B. S. (1993). An examination of event motivations: A case study. Festival Management \& Event Tourism, 1(1), 5-10.

Vontress, C. E. (1979). Cross-cultural counseling: An existential approach. Personnel \& Guidance Journal, 58(2), 117-122.

Wamwara-Mbugua, L. W., \& Cornwell, T. B. (2009). Visitor motivation to attending international festivals. Event Management, 13(4), 277-286.

Wooten, M. H., \& Norman, W. C. (2007). Differences in arts festival visitors based on level of past experience. Event Management, 11(3), 109-120.

Zukin, S. (1998). Urban lifestyles: Diversity and standardisation in spaces of consumption. Urban Studies, 35(5/6), 825 .

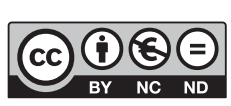

This paper is published under the terms of the Attribution- NonCommercial-NoDerivatives 4.0 International (CC B Y-NC-ND 4.o) License. 